\title{
New DC/DC Converter for Electrolyser Interfacing with Stand-Alone Renewable Energy System
}

\author{
Andrei Blinov (Research Fellow, Tallinn University of Technology), \\ Anna Andrijanovits (Doctoral student, Tallinn University of Technology).
}

\begin{abstract}
This paper presents findings of a $R \& D$ project targeted to the development of a galvanically isolated step-down DC/DC converter for electrolyzer integration with renewable energy systems. The presented converter with an improved control algorithm for the full-bridge active rectifier features reduced energy circulation and switching losses. The performance can be improved under wide input voltage and load variations. The advantages of the converter were verified with a $1 \mathrm{~kW}$ converter prototype and the test results were in full agreement with the expected waveforms. The presented steadystate operation principle and mathematical analysis of the converter based on the simulation and experimental results can be used as design guidelines for component and parameter estimation in practical applications.
\end{abstract}

Keywords - Distributed power generation, energy storage, hydrogen storage, zero current switching, zero voltage switching.

\section{INTRODUCTION}

Use of alternative energy sources is an urgent issue today. Main advantages of renewable energy are zero fuel costs and lower impact on the environment. However, renewable energy sources, such as solar and wind power, are difficult to use due to their stochastic variability. In order for renewable energy to be generally used for regular consumers, the concept of hydrogen use needs to be introduced to stabilize unregulated renewable energy generation [1]-[4]. A typical renewable energy system (RES) must include both short-term and longterm energy storage. A short-term energy storage system is commonly used due to its high round-trip efficiency, convenience for charging/discharging. In addition, it can take care of the effects caused by instantaneous load ripples/spikes, electrolyzer transients and wind energy peaks. However, batteries alone are not appropriate for long-term energy storage because of their low energy density, self-discharge, and leakage. The combination of short-term energy storage with long-term energy storage in the form of hydrogen can improve the performance of stand-alone RES significantly.

Fig. 1 shows a hydrogen-based energy storage system or a hydrogen buffer (HB) consisting of two layers: electrochemical and power electrical stage. The electrochemical stage includes hydrogen production, hydrogen storage and electricity production. In the excess energy periods the hydrogen generation system is connected to the DC-bus of the RES. In this stage electrical energy from the renewable energy source is converted into chemical energy by using water electrolysis and this energy is stored in a tank. In order to stabilize energy production during the absence of the renewable energy, stored hydrogen could be re-used. In this stage, hydrogen is converted into electrical energy by using a fuel cell (FC). The FC takes the hydrogen from the tanks to generate electricity, plus water and heat as by-products. Combination of an energy storage system and an RES allows controllable power production.

To achieve proper voltage matching the main components of the HB should be connected to the DC-bus of RES via different power electronic converters: the electrolyzer is interfaced by help of a step-down DC/DC converter, while the fuel cell is connected by help of a step-up DC/DC converter. In principle, any basic power converter topology can be used to design a power interface for a fuel cell and an electrolyzer. Typically, these converters have a high-frequency voltage matching transformer, which could also perform the function of galvanic isolation demanded in several applications. The main technology development trend here is to reduce the power losses in the interface converters in order to obtain the highest possible energy efficiency of the HB.

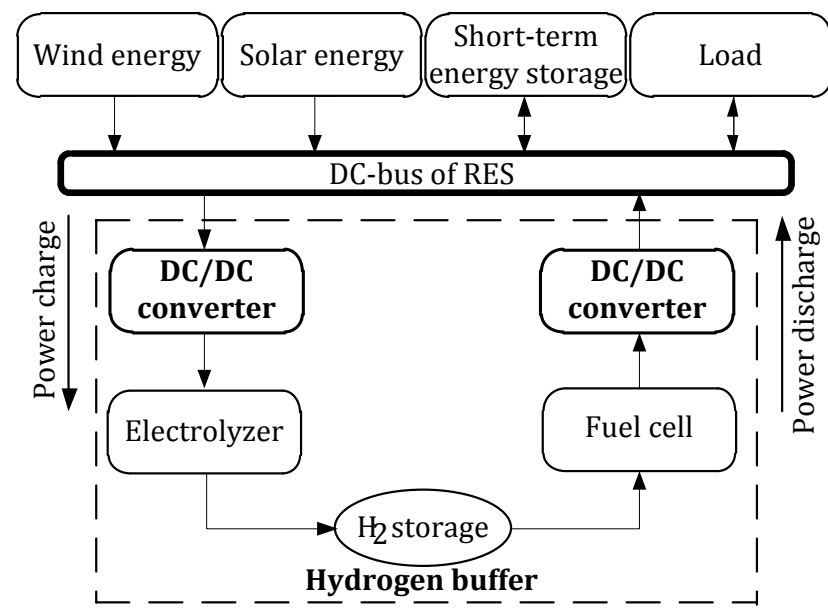

Fig. 1. Energy exchange processes in the hydrogen buffer connected to a stand-alone renewable energy system.

In the analysis of the state-of-the-art converters for the HB application it was stated that the majority of presented topologies are meant for the fuel cell integration to the RES and only minor publications [2], [3], [5]-[7] are related to the interface converters for electrolyzers.

This paper presents a new galvanically isolated step-down DC/DC converter (Fig. 2). The converter has a half-bridge inverter on its primary side, high-frequency step-down transformer and a full-bridge phase-shifted active rectifier based on reverse blocking (RB) switches on the secondary side. 


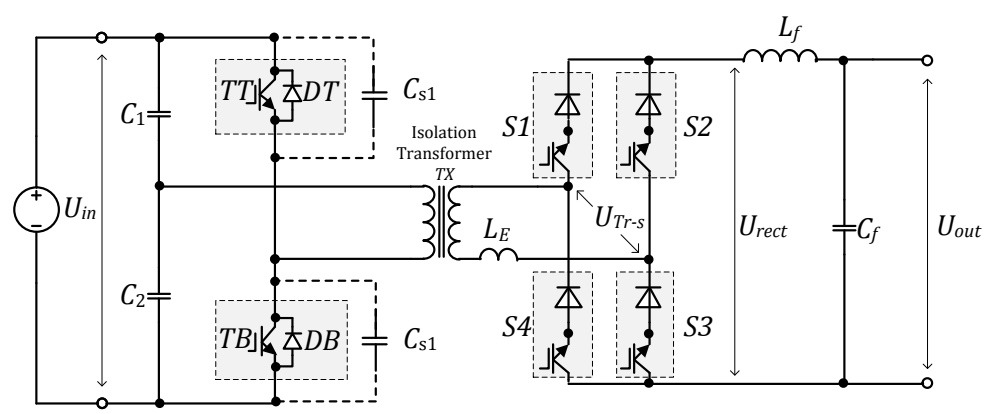

Fig. 2. Investigated half-bridge converter circuit with controlled RB switches at the secondary side.

\section{II.STEP-DOWN DC/DC CONVERTER WITH A FULL-BRIDGE PHASE-SHIFTED ACTIVE RECTIFIER}

The phase-shifted synchronous rectifier concept is a wellknown method to reduce the ringing, increase the efficiency and achieve ZVS (zero voltage switching) of converter switches. The other advantages are the possibility of using non-dissipative capacitive snubbers in the inverter and constant frequency operation, allowing for simple control of the converter. Generally, these converters comprise a half- or a full-bridge inverter, a high-frequency transformer and a rectifier [8], [9]. The rectifier part could be classified as: fullbridge, central-tapped and current-doubler [10].

In converters with a synchronous rectifier the output voltage is generally controlled by the varying delay time between the turn-on of the switches in the rectifier and the turn-on of the IGBTs in the inverter. At the beginning of each half-period, the transformer current will have the same direction as in the previous one and will only change it when the other switch pair in the rectifier turns on. Therefore, at the beginning of each half-period the current will flow through the freewheeling diode of the IGBT module to be turned on next, allowing the ZVS of both inverter transistors. This switching algorithm allows non-dissipative capacitive snubbers to be used in the inverter and the inductive ones in the rectifier. The role of the latter ones could be performed by the transformer leakage inductance. The disadvantage of such control algorithms is the presence of the intervals of energy return from the load to the power supply (time intervals of the opposite sign of the current and voltage of the primary transformer winding during the delay time). If the energy return is not possible, there will be an increase of the input voltage of the inverter and a deviation of the midpoint potential of the capacitor input voltage divider. Moreover, energy circulation corresponds to the generation of the reactive power, resulting in the reduction of the converter power factor and the efficiency due to increased conduction losses. In the case of high input voltage (large periods of energy return), the effects of these drawbacks could be inacceptable. One of the ways to reduce such effects is to increase the capacitance value of the input voltage divider, however, that leads to an increase in the dimensions and cost of the converter.

\section{OPERATING PRINCIPLE}

To overcome the disadvantages of a conventional phaseshifted synchronous rectifier, the control algorithm of the rectifier switches could be modified, at the same time keeping the advantages of the reference phase-shifted control algorithm [11]. A similar concept for the full-bridge converter was first introduced in [12]. The proposed algorithm provides phase-shifted control whereas practically no energy is returned into the power supply. This is achieved by introducing two additional switching states of the rectifier switches. The voltage and current waveforms of the converter are presented in Fig. 3 with the associated switching states shown in Fig. 4.

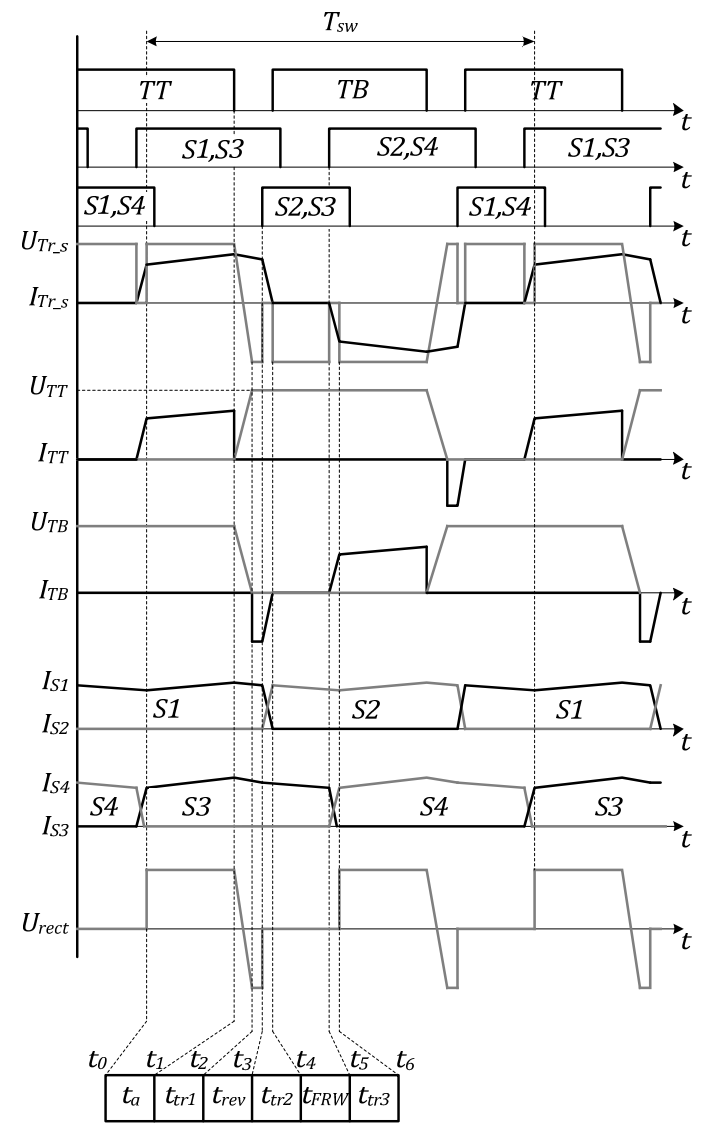

Fig. 3. Generalised operation principle of a proposed converter with a phaseshifted active full-bridge rectifier. 


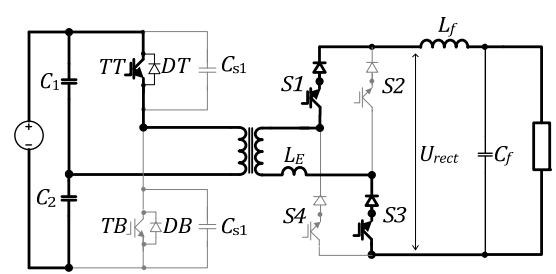

(a)

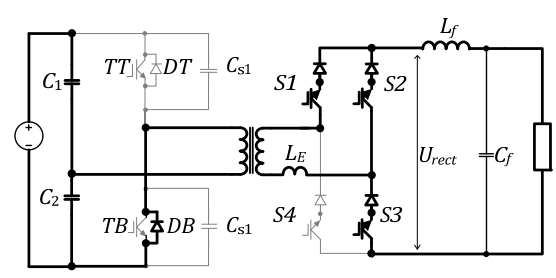

(d)

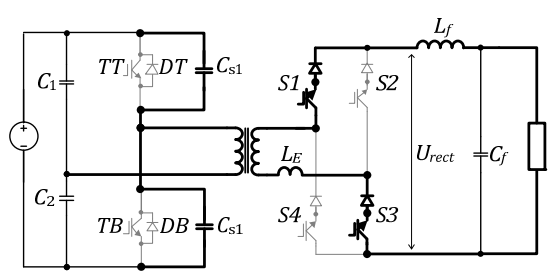

(b)

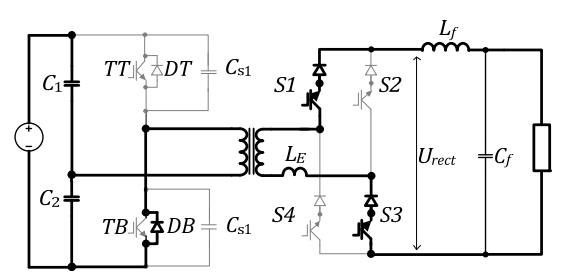

(c)

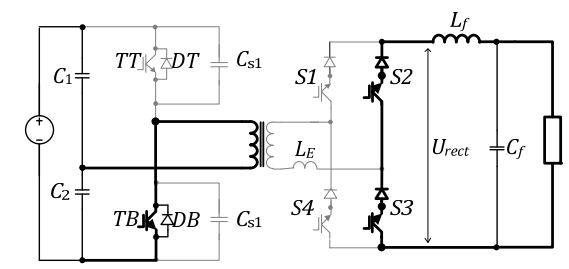

(e)

Fig. 4. Operation modes of the proposed converter.

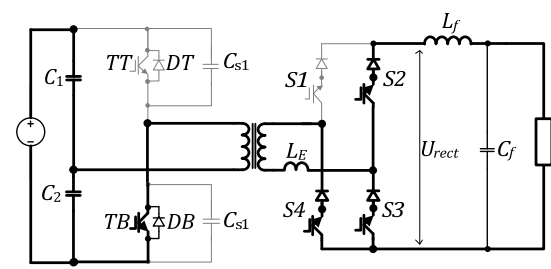

(f)
The following events during the switching half-period could be distinguished:

$t_{0}-t_{1}-$ transistor $T T$ and switches $S 1, S 3$ are conducting (Fig. 4a). The voltage of the transformer primary winding is $+U_{\text {in }} / 2$, and at the output, the voltage of the rectifier is $+U_{T r-s}$. Switch $S 4$ could be turned off with ZCS.

$t_{1}-t_{2}-$ transistor $T T$ is turned off. The transformer voltage and $U_{\text {rect }}$ change their sign as the snubber capacitors are recharged (Fig. 4b).

$t_{2}-t_{3}-$ the snubber capacitors are recharged and the transformer primary voltage reaches $-U_{\text {in }} / 2$. The freewheeling diode $D B$ opens, starting the energy return interval and the transistor $T B$ could be opened with ZVS from now on. The output voltage of the rectifier is now $-U_{T r-s}$ (Fig. 4c). Until the moment $t_{3}$ the processes do not differ from the corresponding ones in the conventional phase-shifted synchronous rectifier.

$t_{3}-t_{4}-$ switch $S 2$ is now opened (Fig. 4 d). The voltage across the transformer secondary drops to zero and the transformer current decreases gradually, as the load current transfers from $S 1$ to $S 2$ with $d i / d t$ limited by the circuit equivalent inductance.

$t_{4}-t_{5}-$ the energy return interval is over, the negative voltage $U_{T r-s}$ is applied to the transformer secondary and switch S1, which can be turned off now with ZCS. Only small magnetising current is flowing through the transformer primary. The load current freewheels through $S 3, S 2, L_{f}$ and the load (Fig. 4e).

$t_{5}-t_{6}-$ switch $S 4$ is opened (Fig. 4f). The voltage across the transformer secondary drops to zero and the transformer and the $T B$ current increase gradually, as the load current transfers from $S 3$ to $S 4$ with $d i / d t$ limited by the circuit equivalent inductance.

The processes are then repeated with the difference that the transistors and the primary side diodes replace each other, so do switches $S 1, S 2$ and $S 3, S 4$.

The control of the output voltage can be achieved by varying the current freewheeling duration $t s$ (time interval $t 3$ t6). The energy return interval (time interval $t 2-t 3$ ) could be constant and should be kept as short as possible in order to maintain high power factor and reduce conduction losses.

\section{SOME DESIGN GUIDELINES}

This section provides guidelines for the selection of the parameters for the experimental converter with the phaseshifted active full-bridge rectifier (AFBR). In order to simplify the calculations it is assumed that the opponents are lossless, the input capacitors and the transformer magnetising inductance are large enough and therefore the input voltage ripple and the magnetising current are negligible. For the introduced modified control algorithm, six PWM channels are used. The inverted control signals of $S 1$ and $S 2$ are shifted by the ratio $D_{\gamma}$ relative to the turn-off of inverter switches (Fig. 5). The inverted control signals for $S 3$ and $S 4$ are shifted by the ratio $D_{s}$ relative to $S 1$ and $S 2$. Rectifier channels have a constant duty cycle and the output voltage is regulated by varying the ratio $D_{s}$. The values of $D_{\gamma}$ and $D_{s}$ are defined as follows:

$$
\begin{gathered}
D_{\gamma}=\frac{t_{3}-t_{1}}{T}, \\
D_{s}=\frac{t_{6}-t_{3}}{T}=\frac{t_{s}}{T} .
\end{gathered}
$$

The active state duty cycle $D_{a}$ of the converter can be calculated by 


$$
D_{a}=\frac{t_{a}}{T}=\frac{T_{s w}-2 \cdot t_{s}-2 \cdot t_{t r l}-2 \cdot t_{r e v}}{2 \cdot T_{s w}}
$$

The output voltage can be expressed by the following equation:

$$
U_{\text {out }}=\frac{N_{s}}{N_{p}} \cdot \frac{U_{\text {in }} \cdot\left(t_{a}-t_{r e v}\right)}{T_{s w}},
$$

and the amplitude voltage across the transformer secondary is

$$
U_{T r-s}=\frac{U_{o u t} \cdot T_{s w}}{2 \cdot\left(t_{a}-t_{r e v}\right)} .
$$

The average and maximum collector currents of inverter transistors are calculated by

$$
\begin{gathered}
I_{C}=\frac{P_{\text {out }} \cdot T}{U_{\text {in }} \cdot\left(t_{a}-t_{\text {rev }}\right)}, \\
I_{C(\max )}=I_{C}+\frac{N_{s}}{N_{p}} \cdot \frac{\Delta I_{\text {ripple }}}{2},
\end{gathered}
$$

where $\Delta I_{\text {ripple }}$ is the filter inductor $L_{f}$ peak-to-peak current ripple.

The inverter switches require a certain dead time $t_{d}$ to recharge snubber capacitors to maintain the ZVS condition, hence the following expression must be satisfied:

$$
t_{d} \geq t_{t r l}=\frac{2 \cdot U_{i n} \cdot C_{s}}{I_{C(\max )}} .
$$

According to this equation, the most demanding point is at the minimum load and the maximum input voltage.

Certain time is required for the current of the rectifier switches to fall to zero during the natural commutation, therefore the rectifier switches should operate with a duty cycle higher than 0.5 to maintain the ZCS condition and exclude the situation when only one transistor in the rectifier is turned on. The additional time required can be equal for all the rectifier switches and is estimated from $t_{t r 2}$ :

$$
D_{\text {rect }} \geq \frac{1}{2}+\frac{t_{\text {tr } 2}}{T_{\text {sw }}}=\frac{1}{2}+L_{E} \cdot \frac{2 \cdot P_{\text {out }} \cdot\left(t_{a}-t_{\text {rev }}\right)}{U_{\text {out }}^{2} \cdot T_{\text {sw }}},
$$

where $L_{E}$ is the equivalent inductance, which is mainly represented by the leakage inductance of the transformer secondary winding.

To estimate the parameters of the output filter inductor it is assumed that the current of the inductor is continuous:

$$
L_{f}=\frac{\left(U_{T r-s}-U_{\text {out }}\right) \cdot t_{a}}{\Delta I_{\text {ripple }}}=\frac{t_{a} \cdot U_{\text {out }}^{2}}{P_{\text {out }} \cdot k_{L}} \cdot\left[\frac{1}{2 \cdot f_{\text {sw }} \cdot\left(t_{a}-t_{\text {rev }}\right)}-1\right],
$$

where $k_{L}$ is the relative current ripple of the output filter inductor :

$$
k_{L}=\frac{\Delta I_{\text {ripple }} \cdot U_{\text {out }}}{P_{\text {out }}} .
$$

The capacitance of the output filter capacitor can be approximated as:

$$
C_{f}=\frac{\Delta I_{\text {ripple }} \cdot t_{a}}{\Delta U_{\text {ripple }}}=\frac{t_{a} \cdot k_{L} \cdot P_{\text {out }}}{k_{U} \cdot U_{\text {out }}^{2}},
$$

where $\Delta U_{\text {out }}$ is the peak-to-peak output voltage ripple and $k_{U}$ is the relative voltage ripple.

$$
k_{U}=\frac{\Delta U_{\text {out }}}{U_{\text {out }}},
$$

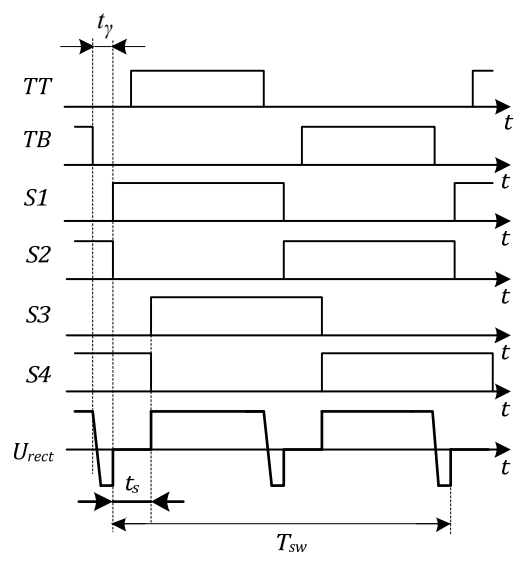

(a)

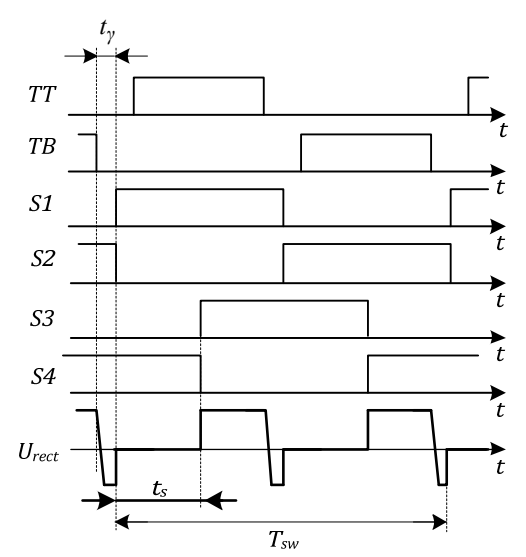

(b)

Fig. 5. New control algorithm for the converter with a phase-shifted active rectifier at maximal (a) and minimal (b) input voltages. 
Fig. 6 presents the relationship between the normalised output voltage $\left(U_{\text {out }} / U_{T r-s}\right)$ and the freewheeling state duty ratio $D_{s}$.

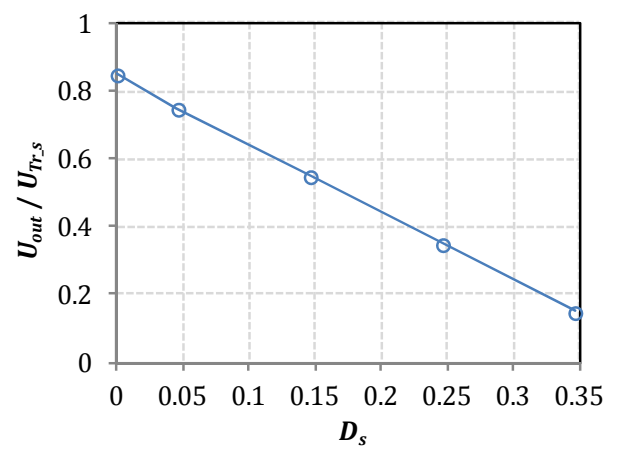

Fig. 6. Output voltage regulation characteristics $(D \gamma=0.025)$.

\section{V.SIMULATION AND EXPERIMENTAL RESULTS}

In order to verify the theoretical approach the proposed converter was simulated using PSIM software. The simulation parameters were selected to the data presented in Table I.

TABLE I

PARAMETERS AND COMPONENTS OF THE EXPERIMENTAL PROTOTYPE

\begin{tabular}{|l|c|c|}
\hline \multicolumn{1}{|c|}{ Parameter } & Symbol & Value / Type \\
\hline Input voltage, $\mathrm{V}$ & $U_{\text {in }}$ & $500 \ldots 620$ \\
\hline Output voltage, $\mathrm{V}$ & $U_{\text {out }}$ & 70 \\
\hline Switching frequency, $\mathrm{kHz}$ & $f_{\text {sw }}$ & 10 \\
\hline Transformer turns ratio & $N_{s} / N_{p}$ & 0.5 \\
\hline Output filter capacitance, $\mathrm{uF}$ & $C_{f}$ & 220 \\
\hline Output filter inductance, $\mathrm{mH}$ & $L_{f}$ & 1.5 \\
\hline Inverter switch & $T T, T B$ & BSM75GB120DLC \\
\hline Rectifier switch & \multirow{2}{*}{$S 1-S 4$} & IXFX 48N60P \\
\cline { 1 - 1 } Rectifier diode & $P_{\text {out }}$ & ON MBR40250 \\
\hline Output power, $\mathrm{W}$ & & 2000 \\
\hline
\end{tabular}

As shown in Fig. 7, the simulation results were in full agreement with the estimated waveforms.
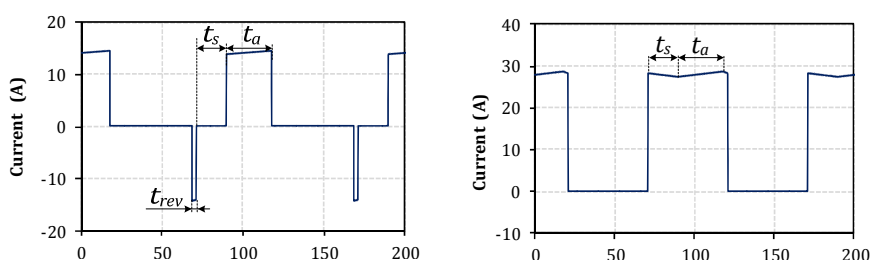

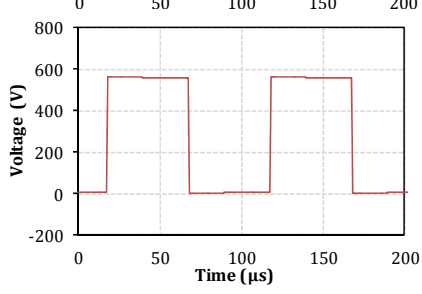

(a)

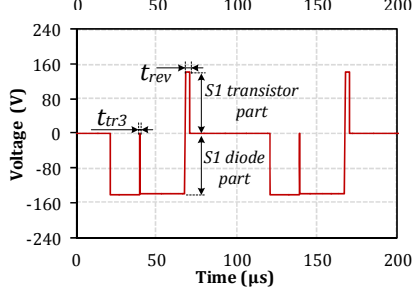

(b)
Fig. 7. Simulated voltage and current waveforms of the TT IGBT module (a) and $S 1$ switch (b).

To experimentally validate a theoretical background a small-scale prototype with the output power of $1 \mathrm{~kW}$ was assembled. Six independent PWM channels were used. Two channels with small dead time were used to drive IGBTs in the inverter and four channels were used to control the rectifier. As mentioned, rectifier switches should have reverse blocking capability. In the prototype, MOSFETs with series connected diodes were used. In practical applications these switches could be replaced by reverse-blocking IGBTs or fast thyristors for reduced power dissipation during the on- state. The main parameters and components are presented in Table I.

The experimental waveforms are presented in Fig. 8. As shown, the test results completely correspond to the theoretically predicted waveforms.
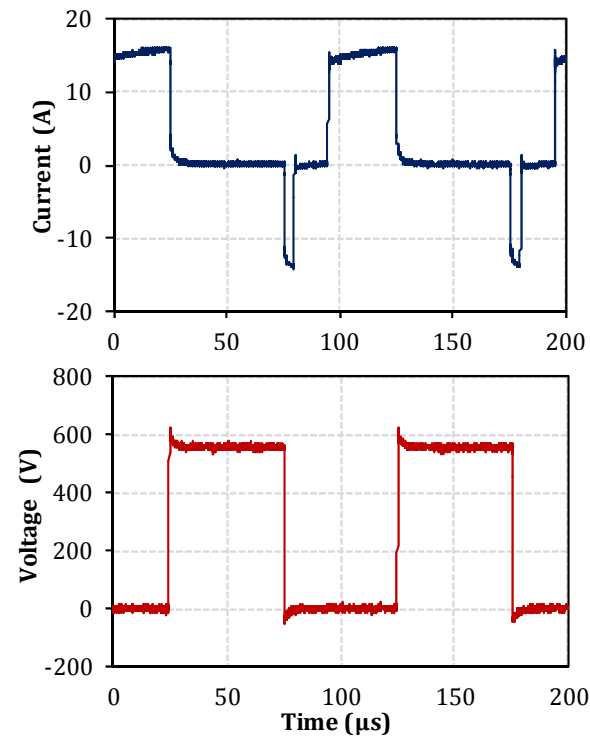

(a)
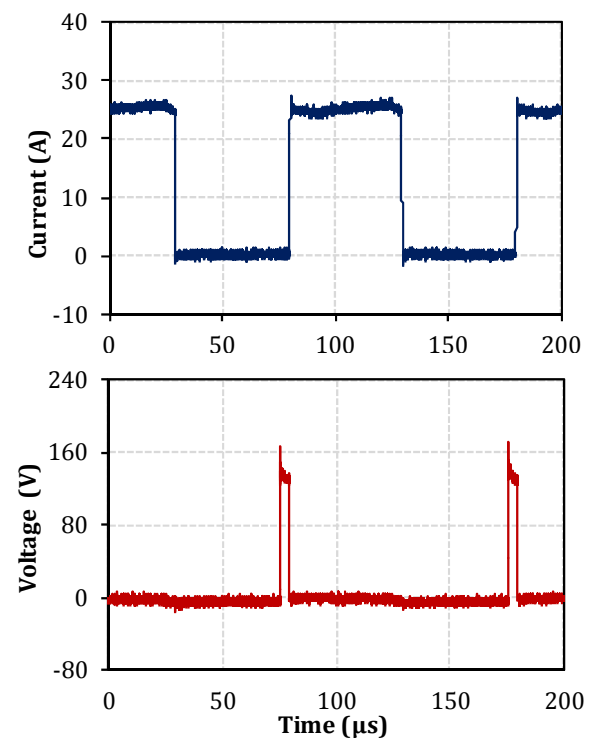

(b)

Fig. 8. Experimental voltage and current waveforms of the TT IGBT module (a); $S 1$ transistor (b) (Uin=350 V; $f s w=10 \mathrm{kHz}, 800 \mathrm{~W}$ load). 


\section{CONCLUSIONS}

This paper presents a novel galvanically isolated step-down $\mathrm{DC} / \mathrm{DC}$ converter for electrolyzer integration with stand-alone renewable energy systems. The design of the converter with several recommendations and guidelines are outlined. To validate the topology, the simulation and experimental results are presented and discussed. According to the results, the presented step-down DC/DC converter topology with a phaseshifted active rectifier could be one of the most promising candidates for high-power conversion systems due to its reduced switching losses and a wide regulation range.

\section{REFERENCES}

[1] Andrijanovitš, A.; Egorov, M.; Lehtla, M.; Vinnikov, D. "New Method for Stabilization of Wind Power Generation Using an Energy Storage Technology". Journal on Agronomy Research, vol. 8, (S1), pp. 12-24, May 2010

[2] Cavallaro, C.; Chimento, F.; Musumeci, S.; Sapuppo, C.; Santonocito, C. "Electrolyser in H2 Self-Producing Systems Connected to DC Link with Dedicated Phase Shift Converter", International Conference on Clean Electrical Power, ICCEP '2007, pp. 632-638, 21-23 May 2007.

[3] Cavallaro, C.; Cecconi, V.; Chimento, F.; Musumeci, S.; Santonocito, C.; Sapuppo, C. "A Phase-Shift Full Bridge Converter for the Energy Management of Electrolyzer Systems", IEEE International Symposium on Industrial Electronics, ISIE'2007, pp. 2649-2654, 4-7 June 2007

[4] Ugartemendia, J.J.; Ostolaza, X.; Moreno, V.; Molina, J.J.; Zubia; I. "Wind generation stabilization of fixed speed wind turbine farms with hydrogen buffer", 11th. Spanish-Portuguese Conference on Electrical Engineering (11CHLIE), pp. 1-5, 1-4 July 2009

[5] Vinnikov, D.; Hõimoja, H.; Andrijanovits, A.; Roasto, I.; Lehtla, T. Klytta, M. "An improved interface converter for a medium-power windhydrogen system", 2009 International Conference on Clean Electrical Power, pp.426-432, 9-11 June 2009.

[6] Gautam, D.S.; Bhat, A.K.S. "A comparison of soft-switched DC-to-DC converters for electrolyser application", 2006. India International Conference on Power Electronics (IICPE'2006), pp. 274-279, 1921 Dec. 2006.

[7] Andrijanovits, A.; Vinnikov, D.; Roasto, I.; Blinov, A.; , "Three-level half-bridge ZVS DC/DC converter for electrolyzer integration with renewable energy systems," Environment and Electrical Engineering (EEEIC), 2011 10th International Conference on , vol., no., pp.1-4, 8-11 May 2011

[8] Yingqi Zhang; Sen, P.C.; "A new ZVS phase-shifted PWM DC/DC converter with push-pull type synchronous rectifier", Canadian
Conference on Electrical and Computer Engineering, IEEE CCECE'03, vol.1, pp. 395- 398 vol.1, 4-7 May 2003

[9] Hong Mao; Abu-Qahouq, J.A.; Shiguo Luo; Batarseh, I.; "Zero-voltageswitching (ZVS) two-stage approaches with output current sharing for $48 \mathrm{~V}$ input DC-DC converter", Nineteenth Annual IEEE Applied Power Electronics Conference and Exposition, APEC'04, vol.2, pp. 1078- 1082 vol.2, 2004

[10] Chiu, H.J.; Lin, L.W.; Mou, S.C.; Chen, C.C.; "A soft switched DC/DC converter with current-doubler synchronous rectification", The 4th International Power Electronics and Motion Control Conference, IPEMC'04, vol.2, pp.526-531 Vol.2, 14-16 Aug. 2004

[11] Blinov, A.; Ivakhno, V.; Zamaruev, V.; Vinnikov, D.; Husev, O. "A Novel High-Voltage Half-Bridge Converter with Phase-Shifted Active Rectifier", IEEE International Conference on Industrial technology, ICIT'2012, pp.967-970, 19-21 March 2012.

[12] Moisseev, S.; Soshin, K.; Sato, S.; Gamage, L.; Nakaoka, M.; "Novel soft-commutation DC-DC power converter with high-frequency transformer secondary side phase-shifted PWM active rectifier", IEE Proceedings - Electric Power Applications, vol.151, no.3, pp. 260- 267, 8 May 2004.

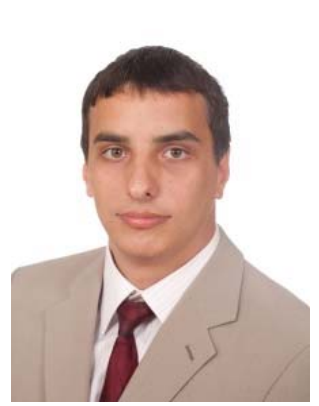

Andrei Blinov received his B.Sc. and M.Sc. techn. in electrical drives and power electronics from Tallinn University of Technology, Tallinn, Estonia, in 2005 and 2008, respectively. From 2008 he pursues doctoral studies in Tallinn University of Technology.

Andrei Blinov is a Research Fellow in the Department of Electrical Drives and Power Electronics, Tallinn University of Technology. His research interests are in simulation and research of switchmode power converters, semiconductor heat dissipation and different cooling systems.

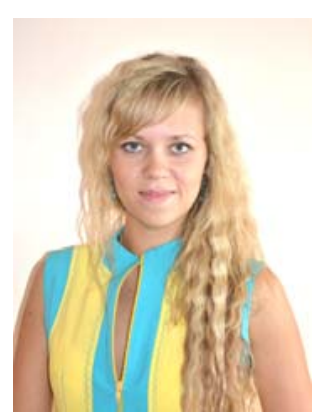

Anna Andrijanovitsh received B.Sc. and M.Sc degrees in electrical engineering from Tallinn University of Technology, Tallinn, Estonia, in 2006 and 2008, respectively.

She is presently $\mathrm{PhD}$ student in the Department of Electrical Drives and Power Electronics, Tallinn University of Technology.

Her research interests include switchmode power converters, modeling and simulation of power systems, applied design of power converters and development of energy storage systems. 